\title{
PENGARUH GAYA KEPEMIMPINAN TERHADAP KINERJA KARYAWAN PADA PERUSAHAAN UMUM PERCETAKAN NEGARA REPUBLIK INDONESIA CABANG SURAKARTA
}

\author{
Michael Manurung \\ Dosen Fakultas Ekonomi Universitas Mpu Tantular, Jakarta Timur \\ Email: michaelmanurung.akt@gmail.com
}

\begin{abstract}
ABSTRAK
Penelitian ini bertujuan untuk menganalisis pengaruh gaya kepemimpinan terhadap kinerja karyawan pada Perusahaan Umum Percetakan Negara Republik Indonesia cabang Surakarta. Pengumpulan data dilakukan melalui penyebaran kuesioner, wawancara dan dilaksanakan pada 43 karyawan Perusahaan Umum Percetakan Negara Republik Indonesia cabang Surakarta. Analisis data pada penelitian ini menggunakan bantuan SPSS versi 23. Jumlah sampelnya diambil secara keseluruhan karena jumlah populasinya kurang dari 100 orang. Penelitian ini meliputi uji validitas dengan analisis faktor, uji reliabilitas dengan Alpha Cronbach, uji asumsi klasik, uji korelasi dan uji parsial untuk menguji dan membuktikan hipotesis penelitian. Hasil penelitian menunjukkan bahwa secara parsial variabel gaya kepemimpinan berpengaruh secara positif dan signifikan terhadap kinerja karyawan Perusahaan Umum Percetakan Negara Republik Indonesia cabang Surakarta sebesar 0,772, artinya gaya kepemimpinan benar-benar dapat meningkatkan kinerja karyawan Perusahaan Umum Percetakan Negara Republik Indonesia cabang Surakarta.
\end{abstract}

Kata kunci: Gaya Kepemimpinan, dan Kinerja Karyawan

\section{PENDAHULUAN}

\section{Latar Belakang}

Ditahun 2019 sekarang ini bisnis pada bidang grafika/percetakan masih menunjukkan potensi yang cukup besar. Sekalipun memang bisnis media online semakin tumbuh pesat bersaing dengan bisnis grafika/percetakan namun dunia percetakan masih memperlihatkan pertumbuhannya dengan melakukan inovasi, efektifitas dan efisiensi, sehingga sampai saat ini tahun 2019 masih banyak orang, perusahaan maupun instansi pemerintahan yang membutuhkan percetakan. Memang industri grafika adalah industri yang unik. Sekalipun sering timbul berbagai masalah, tetapi hal tersebut tidak mengurangi minat orang untuk berinvestasi di bidang ini. Berinvestasi di bidang grafika memang sangat menjanjikan bagi orang-orang yang ulet, pantang menyerah, berkemampuan tinggi, fleksibel, dan benar- 
benar yakin bahwa bisnis di bidang grafika tidak akan pernah mati. Hal itu memang cukup beralasan, karena pada kenyataannya semua orang dalam kehidupannya pada tingkatan manapun selalu memerlukan produk cetakan, hasil karya industri grafika.

Apabila ditinjau lebih jauh permasalahan umum yang ada di dalam perusahaan percetakan adalah dari sisi pengelolaan, seperti :

1. Mempertahankan pelanggan.

2. Mengikuti perkembangan teknologi dan peralatan produksi.

3. Menerapkan sistem produksi.

4. Bekerja efisien dan efektif.

5. Pemahaman alat dan bahan produksi.

Adapun salah satu Badan Usaha Milik Negara yang terjun dalam bisnis grafika/percetakan adalah Perusahaan Umum Percetakan Negara Republik Indonesia (Perum PNRI) yang berdiri sejak tahun 1809 dengan nama "Lands Drukkerij"', sebelum namanya menjadi Percetakan Negara Republik Indonesia (1950), sudah puluhan tahun berkecimpung dalam bisnis ini yang tentunya sudah sangat berpengalaman di bidang grafika/percetakan, yang mana perusahaan ini telah memiliki cabang di 9 daerah dari barat ke timur Indonesia. Salah satu komponen yang sangat penting dalam menjawab tantangan ditinjau dari sisi manajemennya saat ini adalah diperlukannya pemimpin yang tangguh, baik yang ditempatkan di pusat maupun di cabang-cabang daerah. Pemimpin yang baik tentunya mampu menggunakan sumber daya perusahaan agar kinerja karyawan tetap terjaga dengan baik bahkan meningkat.

Salah satu cabang PNRI yang menjadi objek pengamatan adalah cabang Surakarta. Hal ini dilihat dari kinerja penjualan akhir-akhir ini menurun sementara kepala cabang kira-kira sudah 10 tahun lamanya menjabat. Penulis tertarik untuk melakukan penelitian di cabang Surakarta karena menurut pengamatan penulis pengaruh kepemimpinan sangatlah signifikan mempengaruhi kinerja karyawan dan tentunya akan mempengaruhi laju pertumbuhan penjualan suatu entitas.

\section{Pembatasan Masalah}

Dari latar belakang masalah sebagaimana telah diuraikan diatas, ternyata masalah kinerja karyawan merupakan masalah yang luas dan kompleks serta banyak juga faktor yang mempengaruhinya. Oleh sebab itu mengingat akan adanya keterbatasan peneliti dalam hal 
biaya, tenaga juga waktu, maka peneliti memutuskan membatasi penelitian ini pada Pengaruh Gaya Kepemimpinan Terhadap Kinerja Karyawan Pada Perusahaan Umum Percetakan Negara Republik Indonesia cabang Surakarta, yang mana 1 variabel independen tersebut diatas menurut pengamatan peneliti berpengaruh signifikan terhadap kinerja karyawan.

\section{Rumusan Masalah}

Berdasarkan pembatasan masalah diatas, maka permasalahan dalam penelitian ini dapat dirumuskan menjadi apakah gaya kepemimpinan berpengaruh secara signifikan terhadap kinerja karyawan pada perusahaan?

\section{TINJAUAN PUSTAKA}

\section{Gaya Kepemimpinan}

Kepemimpinan adalah proses mengarahkan dan mempengaruhi aktivitas-aktivitas tugas dari orang-orang dalam kelompok. Kepemimpinan berarti melibatkan orang lain, yaitu bawahan atau karyawan yang dipimpin. (Sunarto, 2003).

Winardi (2004) juga menyatakan defenisi dari pemimpin adalah: seseorang yang karena kecakapan-kecakapan pribadinya dengan atau tanpa pengangkatan resmi dapat mempengaruhi kelompok yang dipimpinnya untuk menggerakkan usaha bersama kearah pencapaian sasaran-sasaran tertentu. Seirama dengan itu menurut Kartono (2010), kepemimpinan bukan lagi didasarkan kepada bakat dan pengalaman saja, tetapi pada persiapan secara berencana, dalam melatih calon-calon pemimpin. Semuanya itu dapat dilakukan lewat perencanaan, penyelidikan, percobaan/eksperimen, analisis, supervisi, juga penggemblengan secara sistematis untuk dapat membangkitkan sifat-sifat pemimpin yang benar-benar unggul agar mereka berhasil dalam melaksanakan tugas-tugasnya.

Siagian (2008) menyatakan bahwa, ada 5 (lima) yang menjadi kategori dari gaya kepemimpinan yang dapat digunakan seorang pemimpin, yaitu:

1. Tipe Otokratik.

2. Tipe Paternalistik.

3. Tipe Kharismatik.

4. Tipe Laissez-faire. 
5. Tipe Demokratik.

Pengukuran variable Gaya Kepemimpinan yang digunakan dalam penelitian ini adalah menggunakan skala Likert. Skala Likert adalah metode pengukuran sikap dengan menyatakan setuju atau ketidaksetujuannya terhadap suatu subjek, objek atau kejadian tertentu (Indriantoro dan Supomo, 2014).

\section{Kinerja}

Asal kata kinerja adalah berasal dari job performance atau actual performance (artinya prestasi kerja atau prestasi yang benar-benar dicapai oleh seseorang). Kinerja adalah hasil kerja seorang pegawai untuk mencapai tujuan yang ingin dicapai. Dikutip dari Anwar Prabu Mangkunegara (2007), Kinerja adalah hasil kerja secara kualitas dan kuantitas yang dicapai oleh seorang pegawai dalam melaksanakan tugasnya sesuai dengan tanggung jawab yang diberikan kepadanya.

Rumusan Lembaga Administrasi Negara Republik Indonesia disingkat LAN RI (1999:3), mengemukakan bahwa kinerja adalah gambaran mengenai tingkat pencapaian pelaksanaan suatu kegiatan, program, kebijakasanaan dalam mewujudkan sasaran, tujuan, misi, dan visi organisasi. Konsep ini lebih kepada acuan kinerja suatu organisasi publik yang mana sangat relevan terhadap strategi suatu organisasi yakni menyangkut visi dan misi yang ingin dicapai.

Ada juga Sedarmayanti (2011) yang menyatakan bahwa kinerja merupakan terjemahan dari kata performance yang memiliki arti sebagai sebuah hasil kerja seorang pegawai atau pekerja, sebuah proses manajemen yang mana hasil kerja tersebut harus memiliki sebuah bukti konkret yang juga dapat diukur.

Menurut Mathis \& Jakson (2006), kinerja karyawan adalah apa yang dilakukan dan tidak di lakukan oleh karyawan.

Adapun faktor-faktor yang dapat mempengaruhi kinerja menurut Anoraga (2005) adalah mencakup : daya tarik pekerjaan, upah (insentif), kemauan dan perlindungan kerja, pengetahuan, lingkungan dan suasana kerja, harapan pengembangan karir, keterlibatan dalam kegiatan organisasi, perhatian dan kepemimpinan atasan. Ditinjau dari pernyataan Bateman, 
Feris dan Strasser (2005), bahwa faktor-faktor yang mempengaruhi kinerja adalah antara lain: kemampuan, upaya, kesulitan tugas. Namun dapat terjadi juga bahwa sejumlah faktor dapat mempengaruhi kinerja seperti : perilaku, sikap, tindakan-tindakan rekan sekerja, bawahan atau pimpinan, kendala-kendala sumber daya dan keadaan ekonomi.

Menurut Mill (2005) terdapat beberapa faktor yang mempengaruhi dapat kinerja pegawai/karyawan yakni : 1) keterampilan kerja, 2) motivasi, 3) lingkungan kerja, dan 4) sikap.

Pengukuran variable Kinerja yang digunakan dalam penelitian ini adalah menggunakan skala Likert. Skala Likert adalah metode pengukuran sikap dengan menyatakan setuju atau ketidaksetujuannya terhadap suatu subjek, objek atau kejadian tertentu (Indriantoro dan Supomo, 2014).

\section{Penelitian Terdahulu}

Penelitian pertama terdahulu dilakukan oleh Hotma Tua Hutapea (2011), penelitian ini bertujuan untuk menganalisis pengaruh gaya kepemimpinan dan kepuasan kerja terhadap kinerja karyawan pada CV. Abitas Barata Medan. Populasi adalah karyawan CV Abitas Barata Medan yang berjumlah 58 orang. Hasil uji parsial untuk hipotesis dapat diketahui bahwa secara parsial variabel gaya kepemimpinan memiliki pengaruh yang positif dan sangat signifikan terhadap variabel kepuasan kerja karyawan pada CV Abitas Barata Medan. Gaya kepemimpinan yang selama ini diterapkan oleh pimpinan CV Abitas Barata Medan dapat menimbulkan rasa kepuasan dalam bekerja pada setiap karyawan.

Penelitian kedua terdahulu dilakukan oleh Syamsidar Putri (2016), penelitian ini bertujuan untuk mengetahui bagaimana pengaruh gaya kepemimpinan situasional terhadap kinerja pegawai di Badan Pertanahan Nasional (BPN) Kota Medan. Metode penelitian yang digunakan adalah bersifat kuantitatif dengan melakukan penyebaran kuesioner. Populasi penelitian yaitu sebanyak 120 orang dan yang menjadi sampel dalam penelitian ini sebanyak $50 \%$ dari jumlah populasi yaitu 60 orang responden. Berdasarkan hasil penelitian yang telah dilakukan dari perhitungan uji antara variabel $\mathrm{X}$ dan variabel $\mathrm{Y}$, maka diperoleh rxy $=0,296$ dengan harga thitung $=2,360$. Hal ini menunjukkan kefisien korelasi adalah signifikan dengan nilai tes statistik thitung>ttabel yang berarti Ha diterima, yaitu ada pengaruh yang positif antara gaya kepemimpinan situasional terhadap kinerja pegawai di Badan Pertanahan Nasional (BPN) Kota Medan. Besarnya pengaruh gaya kepemimpinan situasional terhadap kinerja pegawai di Badan Pertanahan Nasional (BPN) Kota Medan adalah sebesar 8,8\%. 


\section{Rumusan Hipotesis}

Berdasarkan teori yang telah diuraikan sebelumnya diatas maka dapat dirumuskan hipotesis penelitian, sebagai berikut:

1. Diduga gaya kepemimpinan $\left(\mathrm{H}_{1} \mathrm{a}\right)$ berpengaruh secara positif dan signifikan terhadap kinerja karyawan pada perusahaan.

2. Diduga gaya kepemimpinan $\left(\mathrm{H}_{1} 0\right)$ tidak berpengaruh secara positif dan signifikan terhadap kinerja karyawan pada perusahaan.

\section{METODOLOGI PENELITIAN}

\section{Jenis dan Sifat Penelitian}

Berdasarkan jenis masalah yang diteliti, teknik dan alat yang digunakan, maka pendekatan yang digunakan dalam penelitian adalah deskriptif kuantitatif. Penelitian ini adalah jenis penelitian deskriptif kuantitatif, sebab dalam memberikan gambaran (deskripsi) atas suatu peristiwa atau gejala, menggunakan alat bantu statistik. Jenis penelitian yang dilakukan adalah studi kasus yang didukung survey dalam mengumpulkan data mengenai faktor-faktor terkait dengan variabel penelitian. Adapun sifat penelitian adalah eksplanatory research (penjelasan).

\section{Lokasi dan Waktu Penelitian}

Penelitian ini dilakukan di Perusahaan Umum Percetakan Negara cabang Surakarta yang beralamat di Jl. Jenderal Achmad Yani No. 379, Surakarta, Jawa Tengah. Waktu penelitian dilakukan dari bulan April 2019 sampai dengan Oktober 2019.

\section{Populasi}

Menurut Arikunto (1998:104) jika jumlah populasinya kurang dari 100 orang, maka jumlah sampelnya diambil secara keseluruhan, tetapi jika populasinya lebih besar dari 100 orang, maka dapat digunakan rumus Slovin. Karena jumlah karyawan tidak sampai 100 orang, maka semuanya dijadikan sumber bagi data penelitian ini yaitu berjumlah 43 orang untuk dijadikan responden dalam penelitian ini.

\section{Teknik Pengumpulan Data}

Teknik pengumpulan data yang digunakan adalah: 
1. Daftar pertanyaan (Questionnaire), yang diberikan kepada karyawan Perum Percetakan Negara Republik Indonesia cabang Surakarta sebagai responden penelitian.

2. Wawancara (Interview) yang dilakukan dengan pegawai atau pihak-pihak lain yang berhak memberikan informasi dan data mengenai Perum Percetakan Negara Republik Indonesia cabang Surakarta.

3. Studi dokumentasi dilakukan dengan mengumpulkan dan mempelajari dokumen-dokumen yang mendukung penelitian ini, berupa sejarah singkat berdirinya perusahaan, struktur organisasi perusahaan dan jumlah karyawan yang bekerja di perusahaan tersebut.

\section{Jenis dan Sumber Data}

Sumber data dalam penelitian ini adalah:

1. Data primer diperoleh dari wawancara (Interview) dan daftar pertanyaan (Questionnaire).

2. Data sekunder yaitu data yang mendukung data primer yang diperoleh dari dokumendokumen melalui studi dokumentasi.

\section{HASIL PENELITIAN DAN PEMBAHASAN}

\section{Uji Validitas}

Tabel Hasil Pengujian Validitas Instrumen Variabel Gaya Kepemimpinan

\section{Item-Total Statistics}

\begin{tabular}{|l|r|r|r|r|}
\hline & $\begin{array}{c}\text { Scale Mean if } \\
\text { Item Deleted }\end{array}$ & $\begin{array}{c}\text { Scale } \\
\text { Variance if } \\
\text { Item Deleted }\end{array}$ & $\begin{array}{c}\text { Corrected } \\
\text { Item-Total } \\
\text { Correlation }\end{array}$ & $\begin{array}{c}\text { Cronbach's } \\
\text { Alpha if Item } \\
\text { Deleted }\end{array}$ \\
\hline GK01 & 42,77 & 24,135 &, 836 &, 887 \\
GK02 & 42,93 & 26,257 &, 458 &, 904 \\
GK03 & 42,81 & 24,965 &, 764 &, 891 \\
GK04 & 42,67 & 24,082 &, 768 &, 890 \\
GK05 & 42,70 & 24,835 &, 585 &, 899 \\
GK06 & 42,56 & 24,633 &, 616 &, 897 \\
GK07 & 42,95 & 25,950 &, 548 &, 900 \\
GK08 & 42,63 & 24,477 &, 618 &, 897 \\
GK09 & 42,81 & 27,107 &, 252 &, 916 \\
GK10 & 42,63 & 24,477 &, 618 &, 897 \\
GK11 & 42,72 & 24,206 &, 808 &, 888 \\
GK12 & 42,72 & 24,206 &, 808 &, 888 \\
\hline
\end{tabular}

Berdasarkan tabel diatas, diperoleh hasil bahwa nilai rhitung dari semua butir pertanyaan ditunjukkan pada kolom rhitung adalah lebih besar dari rtabel $(0,294)$, sehingga 
dapat dinyatakan bahwa instrumen yang digunakan pada variabel gaya kepemimpinan adalah valid.

Tabel Hasil Pengujian Validitas Instrumen Variabel Kinerja Karyawan

Item-Total Statistics

\begin{tabular}{|l|r|r|r|r|}
\hline & $\begin{array}{c}\text { Scale Mean if } \\
\text { Item Deleted }\end{array}$ & $\begin{array}{c}\text { Scale } \\
\text { Variance if } \\
\text { Item Deleted }\end{array}$ & $\begin{array}{c}\text { Corrected } \\
\text { Item-Total } \\
\text { Correlation }\end{array}$ & $\begin{array}{c}\text { Cronbach's } \\
\text { Alpha if Item } \\
\text { Deleted }\end{array}$ \\
\hline KK01 & 12,63 & 2,001 &, 617 &, 658 \\
KK02 & 12,53 & 1,969 &, 665 &, 634 \\
KK03 & 12,65 & 1,852 &, 459 &, 764 \\
KK04 & 12,14 & 2,171 &, 497 &, 720 \\
\hline
\end{tabular}

Berdasarkan tabel diatas, diperoleh hasil bahwa nilai rhitung dari semua butir pertanyaan ditunjukkan pada kolom rhitung adalah lebih besar dari rtabel $(0,294)$, sehingga dapat dinyatakan bahwa instrumen yang digunakan pada variabel kinerja karyawan adalah valid.

\section{Uji Reliabilitas}

Tabel Hasil Uji Reliabilitas Variabel Penelitian

\begin{tabular}{|l|c|c|c|}
\hline \multicolumn{1}{|c|}{ Variabel } & $\begin{array}{c}\text { Jumlah } \\
\text { Pertanyaan }\end{array}$ & $\begin{array}{c}\text { Koefisien Alpa } \\
\text { Cronbach }\end{array}$ & Keterangan \\
\hline Gaya Kepemimpinan & 12 & 0,904 & Reliabel \\
\hline Kinerja Karyawan & 4 & 0,751 & Reliabel \\
\hline
\end{tabular}

Sumber : Hasil Pengolahan Data SPSS Versi 23

Hasil pengujian pada tabel diatas menunjukkan bahwa semua koefisien Alpha Cronbach yang diperoleh lebih besar dari 0,60. Sehingga butir-butir pernyataan tersebut dapat dinyatakan reliabel. Jadi dapat disimpulkan bahwa kuesioner yang dibuat untuk mengukur gaya kepemimpinan dan kinerja karyawan dinyatakan reliabel atau dapat dipercaya untuk mengukur semua variabel dalam penelitian.

\section{Uji Asumsi Klasik}

\section{Uji Normalitas}




\section{Gambar Grafik Normal P-Plot}

Normal P-P Plot of Regression Standardized Residual

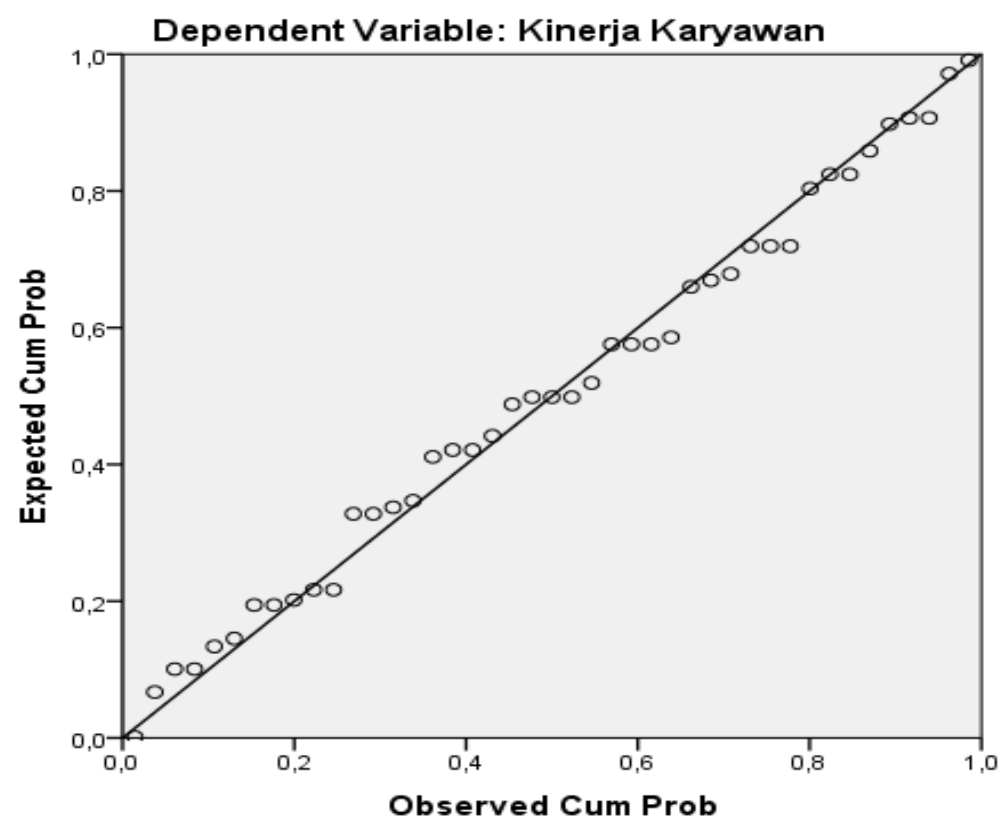

Pada pengujian ini, p-plot yang ditunjukkan pada gambar diatas dapat disimpulkan bahwa model yang digunakan menunjukkan indikasi normal, dimana analisis dari grafik diatas terlihat titik-titik menyebar di sekitar garis diagonal, serta penyebarannya mengikuti arah garis diagonal. Dengan demikian model regresi layak dipakai untuk memprediksi kinerja karyawan pada Perum Percetakan Negara Republik Indonesia cabang Surakarta.

\section{Uji Heteroskedastisitas}

Terlihat gambar di bawah menunjukkan scatterplot antara nilai predicted dengan residual hasil persamaan regresi menyebar secara acak/random tanpa membentuk pola fungsi tertentu, titik-titik data penyebar di atas dan di bawah atau di sekitar angka 0 , dengan kata lain model yang digunakan sudah bebas dari asumsi heterokedastisitas. 


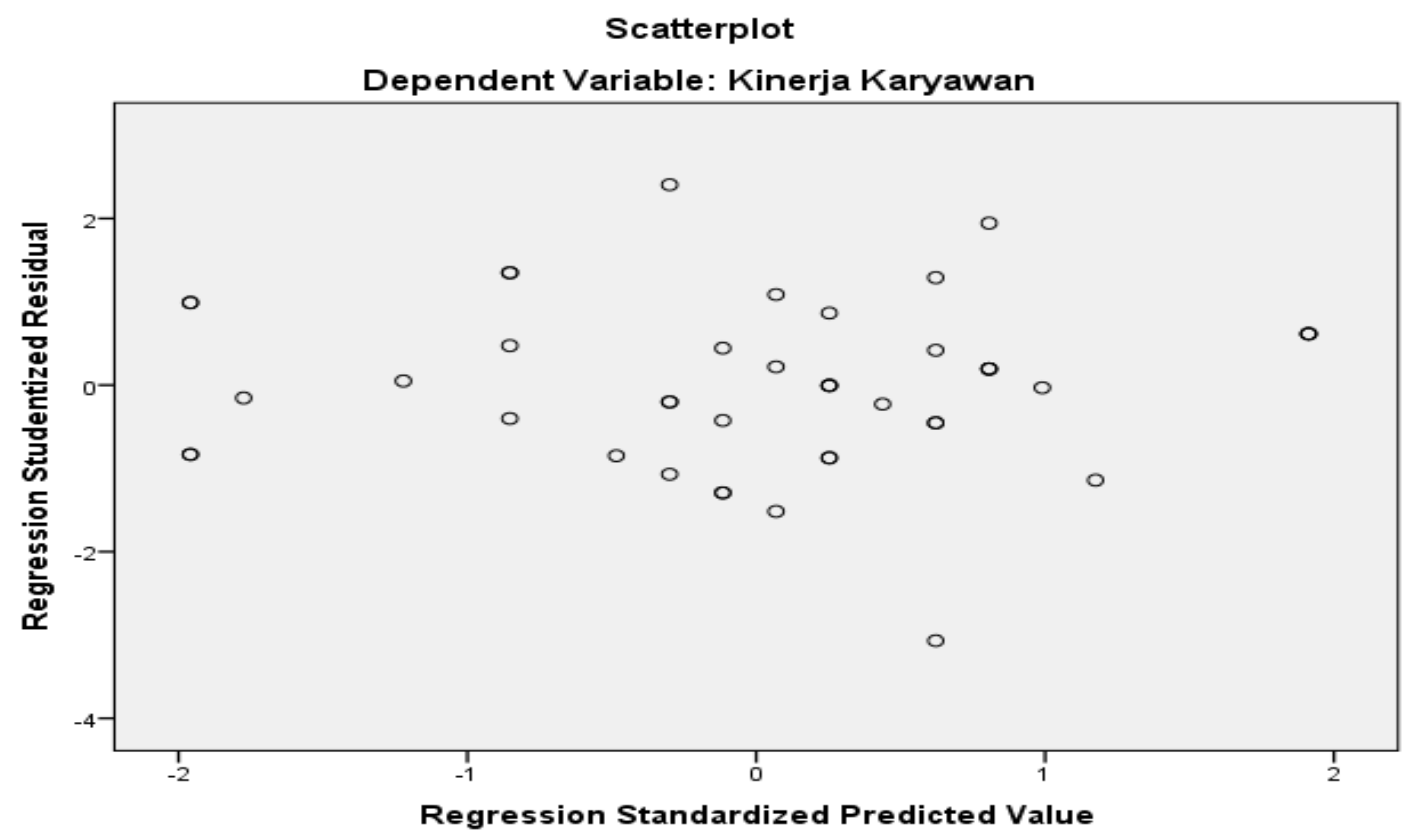

Hasil Analisis Statistik

1. Analisis Korelasi

Tabel Hasil Uji Korelasi Analisis Korelasi

\begin{tabular}{|c|c|c|c|}
\hline \multicolumn{4}{|c|}{ Correlations } \\
\hline & & \begin{tabular}{c|} 
Gaya \\
Kepemimpinan
\end{tabular} & $\begin{array}{c}\text { Kinerja } \\
\text { Karyawan }\end{array}$ \\
\hline $\begin{array}{l}\text { Gaya } \\
\text { Kepemimpinan }\end{array}$ & $\begin{array}{l}\text { Pearson } \\
\text { Correlation } \\
\text { Sig. (2-tailed) } \\
\text { N }\end{array}$ & $\begin{array}{r}1 \\
43\end{array}$ & $\begin{array}{r}, 772 \\
0 \\
43\end{array}$ \\
\hline $\begin{array}{l}\text { Kinerja } \\
\text { Karyawan }\end{array}$ & $\begin{array}{l}\text { Pearson } \\
\text { Correlation } \\
\text { Sig. (2-tailed) } \\
\text { N }\end{array}$ & $\begin{array}{r}, 772 \\
0 \\
43\end{array}$ & $\begin{array}{r}1 \\
43\end{array}$ \\
\hline
\end{tabular}

**. Correlation is significant at the 0.01 level (2-tailed).

Berdasarkan Nilai Signifikansi :

Diketahui variabel Gaya Kepemimpinan dengan Kinerja Karyawan (KK) nilai signifikansinya $0<0,05$ yang berarti terdapat korelasi yang signifikan. 
Berdasarkan Tanda Bintang pada SPSS :

$>\quad$ Dari hasil output di atas, diketahui bahwa nilai pearson correlation yang dihubungkan antara masing-masing variabel mempunyai tanda bintang, hal ini berarti terdapat korelasi yang signifikan antara variabel yang dihubungkan.

\section{Uji T (Uji Parsial)}

\section{Tabel Coefficients Uji t (Parsial)}

\begin{tabular}{|c|c|c|c|c|c|}
\hline \multicolumn{6}{|c|}{ Coefficients $^{a}$} \\
\hline \multirow[b]{2}{*}{ Model } & \multicolumn{2}{|c|}{$\begin{array}{c}\text { Unstandardized } \\
\text { Coefficients }\end{array}$} & \multirow{2}{*}{\begin{tabular}{|c}
$\begin{array}{c}\text { Standardiz } \\
\text { ed } \\
\text { Coefficient } \\
\text { s }\end{array}$ \\
Beta
\end{tabular}} & \multirow[b]{2}{*}{$\mathrm{t}$} & \multirow[b]{2}{*}{ Sig. } \\
\hline & $\mathrm{B}$ & Std. Error & & & \\
\hline 1 (Constant) & 4.639 & 1.557 & & 2.980 & .005 \\
\hline $\begin{array}{l}\text { Gaya } \\
\text { Kepemim } \\
\text { pinan }\end{array}$ & .258 & .033 & .772 & 7.768 & .000 \\
\hline
\end{tabular}

a. Dependent Variable: Kinerja Karyawan

Berdasarkan output coefficients uji t di atas, maka :

Nilai thitung untuk variabel Gaya Kepemimpinan $(2,980)>$ dibandingkan dengan ttabel $(2,019)$, nilai signifikansi sebesar 0,005. Maka H0 ditolak H1 diterima untuk variabel gaya kepemimpinan, dengan demikian maka secara parsial variabel gaya kepemimpinan berpengaruh secara positif dan signifikan terhadap kinerja karyawan.

\section{KESIMPULAN DAN SARAN}

\section{Kesimpulan}

Berdasarkan hasil analisis data yang telah diuraikan pada bab sebelumnya dapat disimpulan bahwa secara parsial variabel gaya kepemimpinan berpengaruh secara positif dan signifikan terhadap kinerja karyawan Perusahaan Umum Percetakan Negara Republik Indonesia cabang Surakarta sebesar 0,772, artinya gaya kepemimpinan benar-benar dapat meningkatkan kinerja karyawan Perusahaan Umum Percetakan Negara Republik Indonesia cabang Surakarta. 


\section{Saran}

1. Pimpinan sebelum mengambil keputusan agar memusyawarahkan terlebih dahulu dan pimpinan diharapkan lebih memperhatikan komunikasi 2 (dua) arah dan mendengar semua pendapat-pendapat sebelum keputusan akhir diambil.

2. Pimpinan dalam pendelegasian tugas haruslah sesuai dengan kemampuan dan keahlian karyawan.

3. Pimpinan hendaklah melakukan pengawasan terhadap tugas yang diberikan kepada karyawan.

\section{DAFTAR PUSTAKA}

Anoraga, Panji. 2005. "Psikologi Kerja”. Rineka Cipta. Jakarta.

Hutapea, Hotma Tua. 2011. "Tesis Analisis Pengaruh Gaya Kepemimpinan Dan Kepuasan Kerja Terhadap Kinerja Karyawan Pada CV Abitas Barata Medan”. Fakultas Ekonomi. Jurusan Ilmu Manajemen. Universitas Sumatera Utara. Medan.

Indriantoro, Nur and Bambang Supomo. 2014. Metodologi Penelitian Bisnis Untuk Akuntansi \& Manajemen. Edisi 1. Cetakan ke-12. Yogyakarta: BPFE.

Jackson, J. H., \& Mathis, R. L.2006. Human Resource Managemen (10th ed.). Jinterface Jakarta: Salemba Empat.

Kartono, Kartini. 2010. Pemimpin dan Kepemimpinan. Apakah kepemimpinan Abnormal itu? Ed.1.-17.Rajawali Pers. 2010. Jakarta.

Keith Davis, dalam buku AA Anwar Prabu Mangkunegara (2007). Evaluasi Kinerja Sumber Daya Manusia. Bandung. PT Refika Aditama.

Putri, Syamsidar, 2016. "Skripsi Pengaruh Kepemimpinan Situasional Terhadap Kinerja Pegawai di Badan Pertanahan Nasional (BPN) Kota Medan”. Fakultas Ilmu Sosial dan Ilmu Politik. Jurusan Ilmu Administrasi Negara. Universitas Sumatera Utara, Medan.

Sedarmayanti. 2011. Manajemen Sumber Daya Manusia, Reformasi Birokrasi dan Manajemen Pegawai Negeri Sipil (cetakan kelima). Bandung : PT Refika Aditama.

Siagian, Sondang P. (2008). Manajemen Sumber Daya Manusia (Edisi Pertama). Jakarta: Binapura Aksara.

Sunarto. 2003. Manajemen Sumber Daya Manusia. Andi Offset. Yogyakarta.

Winardi, J. 2004. Manajemen Perilaku Organisasi. Cetakan Kedua. Kencana. Jakarta. 